\title{
Pattern of $\beta$-Thalassemia and Other Haemoglobinopathies: A Cross-Sectional Study in Bangladesh
}

\author{
M. Mesbah Uddin, Sharif Akteruzzaman, Taibur Rahman, A. K. M. Mahbub Hasan, \\ and Hossain Uddin Shekhar
}

Department of Biochemistry and Molecular Biology, University of Dhaka, Dhaka 1000, Bangladesh

Correspondence should be addressed to Hossain Uddin Shekhar, shekhardu@hotmail.com

Received 7 March 2012; Accepted 24 April 2012

Academic Editors: G. Lucarelli, K. Tani, and B. Wachowicz

Copyright (C) 2012 M. Mesbah Uddin et al. This is an open access article distributed under the Creative Commons Attribution License, which permits unrestricted use, distribution, and reproduction in any medium, provided the original work is properly cited.

Thalassemia and other structural haemoglobinopathies are the major erythrocyte formation disorder prevalent in certain parts of the world including Bangladesh. We investigated 600 cases of anaemic patients referred from various parts of the country for diagnosis and counselling during 3 months (April to June 2011) of time. The most common form of haemoglobin (Hb) formation disorder observed in 600 subjects studied was $\beta$-thalassemia minor (21.3\%). Two other conditions, such as E- $\beta$-Thalassemia and $\mathrm{HbE}$ trait, were also fairly common (13.5 and $12.1 \%$, resp.) in the total subjects studied. Other forms of haemoglobin formation disorders observed were $\mathrm{HbE}$ disease $(9.2 \%), \mathrm{Hb} \mathrm{D} / \mathrm{S}$ trait $(0.7 \%), \beta$-thalassemia major $(0.5 \%)$, and $\delta$ - $\beta$-thalassemia $(0.5 \%)$. The majority of the haemoglobinopathies belonged to neonatal to childhood period ( $0-15$ years), followed by reproductive age group (16-45 years). Few old-age (46+ years) cases were also detected in course of clinical complications.

\section{Introduction}

Haemoglobinopathies are genetic defect that results in abnormal structure of one of the globin chains of the haemoglobin molecule. Defects in these genes can produce abnormal haemoglobin and anaemia. Abnormal haemoglobin appears in one of three basic conditions; structural defects in the haemoglobin molecule, diminished production of one of the two subunits of the haemoglobin molecule (thalassemias), and abnormal association of otherwise normal subunits. The patients suffering from beta-thalassemia major and $\mathrm{HbE} / \mathrm{beta}$-thalassemia do not survive for more than 5 years without blood transfusion [1]. More than 700 haemoglobin variants have been described that involve genes both from alpha and beta gene clusters. Occasionally, someone inherit two different variants from the alpha-globin gene cluster or two different variants from beta-globin gene cluster. This condition is called compound heterozygosity. The nature of two genes inherited determines whether a clinically significant disease state develops. Among these the thalassemias comprise a diverse group of disorders and are broadly classified into $\alpha, \beta, \delta-\beta$ and $\gamma-\delta-\beta$ thalassemias, depending on the globin chain(s), which are insufficiently synthesized [2]. Since humans have $4 \alpha$-globin genes on chromosome 16 and $2 \beta$-globin genes on chromosome 11, symptomatic $\alpha$-thalassemia is rarer than $\beta$ thalassemia. In addition to the transfusion-dependent form of $\beta$-thalassemia, $\beta$-thalassemia major, there are milder conditions that may escape detection until adulthood. Because of their high frequency and severity, the $\beta$-thalassemias pose the most important public health problem.

Inherited disorders of haemoglobin synthesis are, therefore, an important cause of morbidity and mortality worldwide. They place a large burden to the patients, their families, and even their communities. They are generally not curable but can be prevented by population screening, genetic counseling, and prenatal diagnosis [3]. The present study was undertaken to evaluate the spectrum and pattern haemoglobinopathies in a selected population of Bangladesh. 
TABLE 1: Spectrum of haemoglobinopathies in Bangladesh.

\begin{tabular}{lccc}
\hline Type of haemoglobinopathies & Male & Incidence no. $(\%)$ & Total \\
\hline Normal & $166(48.8)$ & $87(33.5)$ & $253(42.2)$ \\
$\beta$-Thalassemia & $57(16.8)$ & $71(27.3)$ & $128(21.3)$ \\
E- $\beta$-Thalassemia & $48(14.1)$ & $33(12.7)$ & $81(13.5)$ \\
Haemoglobin E disease & $25(7.3)$ & $30(11.5)$ & $55(9.2)$ \\
Haemoglobin E trait & $38(11.2)$ & $35(13.4)$ & $73(12.1)$ \\
$\delta$ - $\beta$-Thalassemia & $1(0.3)$ & $2(0.8)$ & $3(0.5)$ \\
$\beta$-Thalassemia major & $2(0.6)$ & $1(0.4)$ & $3(0.5)$ \\
Haemoglobin D/S trait & $3(0.9)$ & $1(0.4)$ & $4(0.7)$ \\
\hline Total & $340(100.0)$ & $260(100.0)$ & $600(100.0)$ \\
\hline
\end{tabular}

\section{Materials and Methods}

2.1. Study Subjects. A total of 600 individuals were recruited in this study. The samples were collected from different hospitals located at Dhaka City during April to June 2011. They were suspected of suffering from anaemia and referred to these hospitals from peripheral regions.

The samples were analyzed at the Department of Biochemistry and Molecular Biology, Dhaka University. Written informed consent was obtained from the study participants and local ethical review committee approved the design of the study.

2.2. Blood Samples. About 2-3 mL intravenous blood samples were collected after obtaining informed consent using EDTA (ethylene diamine tetra acetic acid) as anticoagulants by disposable syringes and needles from each individual free of blood transfusions.

2.3. Haematological Analysis. The Sysmex XE-2100 system Haematology analyzer (Sysmex Corporation, Kobe, Japan) was used to determine peripheral cell count and red blood cell indices (RBC, $\mathrm{Hb} \%, \mathrm{HCT}, \mathrm{MCV}, \mathrm{MCH}$, and $\mathrm{MCHC}$ ) using standard procedure [4] that employed RF/DC detection method, hydrodynamic focusing, flow cytometry method and SLS-haemoglobin method.

2.4. Haemoglobin Electrophoresis. Haemoglobin electrophoresis was carried out on agarose gel using the Hydragel K20 System (Sebia, Issy-les-Moulineaux, France). The resulting electropherograms were evaluated visually for pattern abnormality. Scanning densitometry was used to determine the relative concentration of individual haemoglobin fraction.

2.5. Statistical Analysis. Statistical analysis was carried out using SPSS statistical package (version 11.5). Analysis of variance (ANOVA) of the data was used to detect overall difference in group means. Differences among group means were assessed using least significant difference (LSD).

\section{Results}

Out of 600 cases, $253(42.2 \%)$ cases were found normal and $347(57.8 \%)$ had one or the other form of haemoglobinopathies. Out of 347 abnormal cases, 174 (50.1\%) were males and 173 (49.8\%) were females, which gives an equal incidence in both males and females.

Table 1 represents the spectrum of haemoglobinopathies encountered during three months of time and Figure 1 depicted the electropherograms of different types of haemoglobinopathies. It is important to note here that $\beta$-thalassemia minor is the most common form of haemoglobinopathy $(21.3 \%)$, followed by E- $\beta$-thalassemia (13.5\%), $\mathrm{HbE}$ trait (12.1\%), $\mathrm{HbE}$ disease (9.2\%), $\mathrm{Hb}$ $\mathrm{D} / \mathrm{S}$ trait $(0.7 \%), \beta$-thalassemia major $(0.5 \%)$, and $\delta$ - $\beta$ thalassemia $(0.5 \%)$, respectively. Though the study was conducted in Dhaka City, this data represent an overall picture of the country, because most of the patients were referred from peripheral regions, where such investigation facility is not available.

Table 2 represents an age- and sex-wise distribution of cases of different haemoglobinopathies. It is apparent from the table that majority of the cases of haemoglobinopathy belong to neonatal to childhood period ( $0-15$ years) followed by reproductive age group (16-45 years) and only a few cases of old age (46+ years) who were detected when they face clinical complications.

As shown in Table 3, patients of $\beta$-thalassemia minor had milder anemia with decreased total $\mathrm{Hb}(P<0.001)$ and $\mathrm{HbA}$ $(P<0.001)$ and a slight increase in $\mathrm{HbA}_{2}, \mathrm{E}$, and $\mathrm{F}$ compared to normal subjects. $\mathrm{E}$ - $\beta$-thalassemia patients suffered severe anaemia with significant decrease in total $\mathrm{Hb}(P<0.001)$ and $\mathrm{HbA}(P<0.001)$. There was significant increase in $\mathrm{HbE}(P<$ $0.001)$ and $\mathrm{F}(P<0.001)$ even compared to $\beta$-thalassemia minor group with hypochromia and microcytosis. Patients with $\mathrm{HbE}$ disease suffered anaemia of same magnitude as $\mathrm{E}-\beta$-thalassemia patients. The elevation of $\mathrm{HbE}$ and $\mathrm{F}$ was higher in this group than $\beta$-thalassemia minor group but lower than that of E- $\beta$-thalassemia group. In $\mathrm{HbE}$-trait there was no sign of anaemia, still there was a significant increase in $\mathrm{HbE}(P<0.001)$ level as found in HbE disease compared to $\beta$-thalassemia minor group. $\beta$-Thalassemia major patients had severe anaemia with significant decrease in total $\mathrm{Hb}$ and 

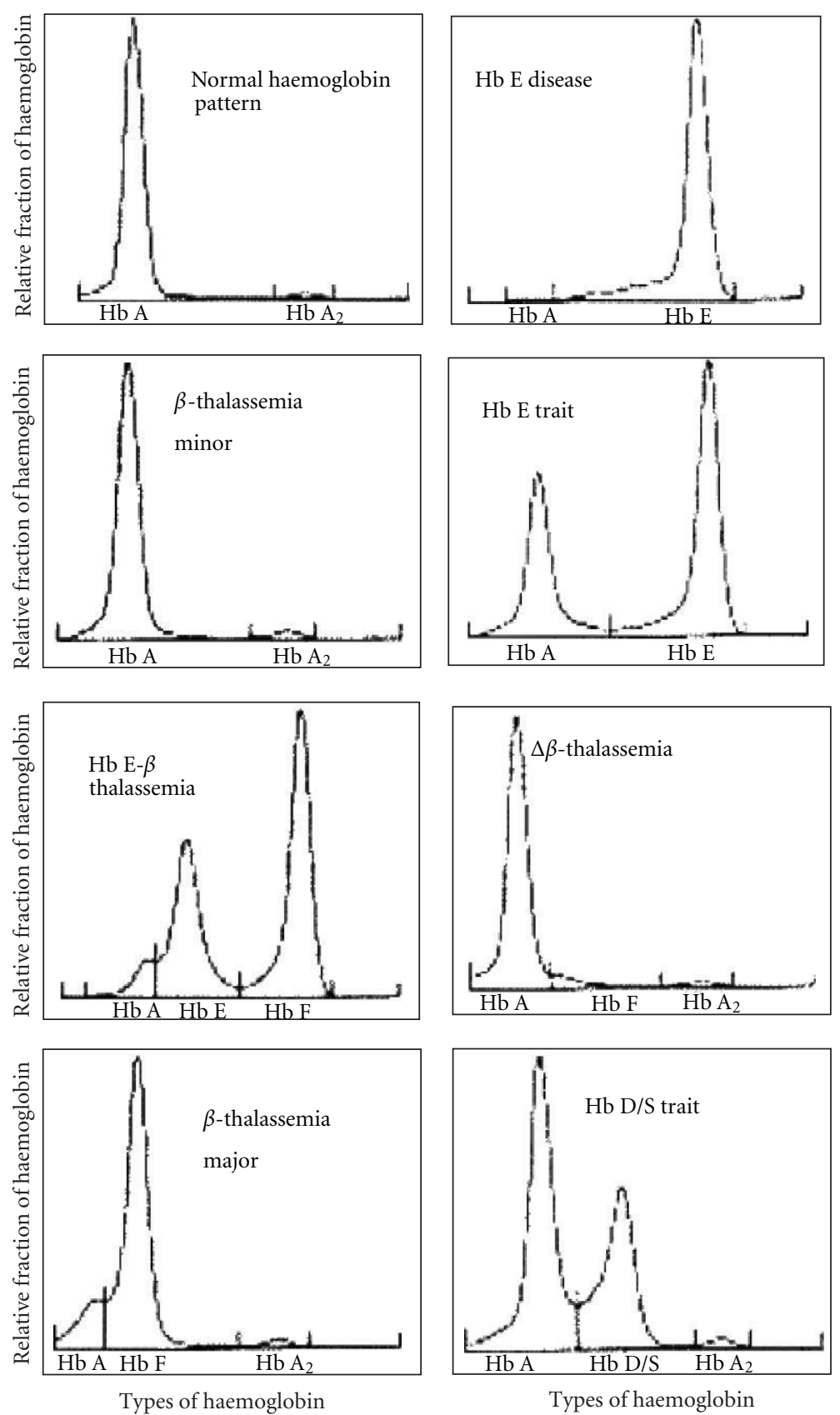

FIGURE 1: Electropherograms showing different types of haemoglobinopathies.

TABle 2: Age- and sex-wise distribution of cases of different haemoglobinopathies.

\begin{tabular}{lccc}
\hline Age group (Years) & \multicolumn{3}{c}{ Incidence no. (\%) } \\
& Male & Female & $193(55.7)$ \\
\hline $0-15$ & $112(64.4)$ & $81(46.8)$ & $136(39.1)$ \\
$16-45$ & $54(31.0)$ & $82(47.4)$ & $18(5.2)$ \\
$46+$ & $8(4.6)$ & $10(5.8)$ & $347(100.0)$ \\
\hline Total & $174(100.0)$ & $173(100.0)$ & \\
\hline
\end{tabular}




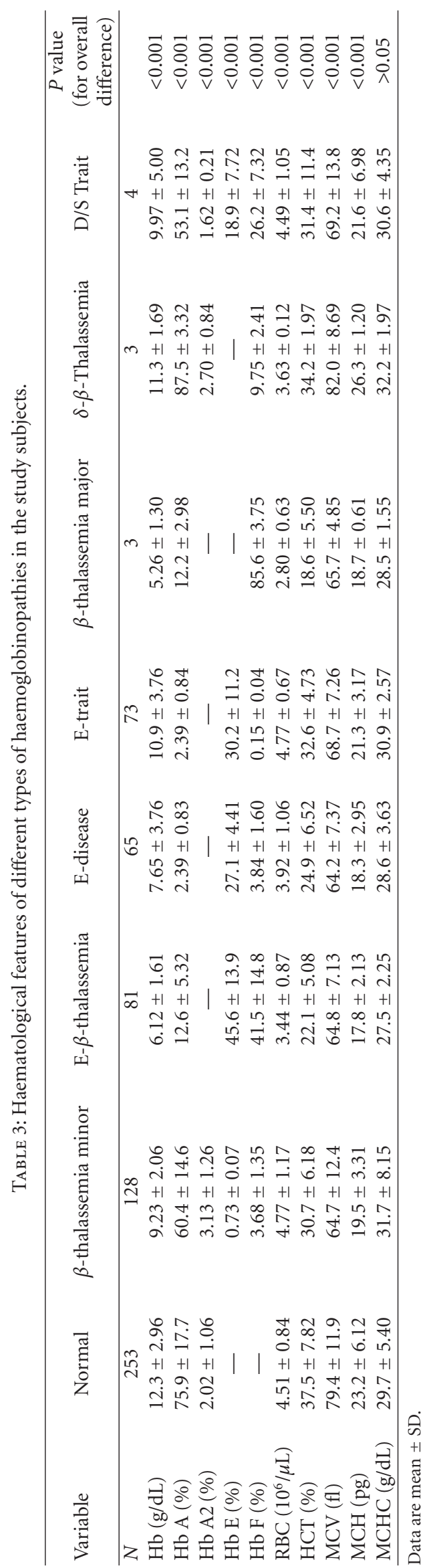


RBC count and showed highest increase in HbF levels among all the groups studied. $\delta$ - $\beta$-thalassemia and $\mathrm{D} / \mathrm{S}$ trait groups showed milder anaemia with slight increase in $\mathrm{HbA}_{2}$ and $\mathrm{HbF}$ levels. However, $\delta$ - $\beta$-thalassemia group did not show an increase in $\mathrm{HbE}$ levels as it was evident in D/S trait group.

\section{Discussion}

Haemoglobinopathies are monogenic disorders of erythrocyte formation that has a widespread prevalence extending from Mediterranean zone, Middle East, Indian subcontinent, and parts of Southeast Asia [5]. Though the exact data regarding the prevalence and spectrum of haemoglobinopathies in Bangladesh is not known, it seems to be increasing. If the disease continues to pass vertically, it may take the form of epidemic. Since there is no effective treatment of the disease, the only way to prevent the disease is carrier detection and awareness among the people about this emerging epidemic. This study, therefore, provides a comprehensive data on the pattern of spectrum of haemoglobinopathies in Bangladesh.

Present study was conducted on 600 individuals referred to different hospitals at Dhaka City between April to June 2011. Among the 600 cases studied, $42.2 \%$ were found to be normal and $57.8 \%$ had one or the other forms of anaemia (Table 1). Out of 347 abnormal cases equal incidence in males $(50.1 \%)$ and females $(49.8 \%)$ was observed (Table 2$)$. Most common haemoglobinopathies observed were $\beta$ thalassemia minor (21.3\%), E- $\beta$-thalassemia (13.5\%), haemoglobin $\mathrm{E}$ disease $(9.2 \%)$, and haemoglobin $\mathrm{E}$ trait $(12.1 \%)$. Several other studies also have documented such high frequency of these haemoglobin formation disorders in neighbouring and other Southeast Asian countries [6-9]. Other less common haemoglobinopathies observed were $\delta$ - $\beta$-thalassemia $(0.5 \%), \beta$-thalassemia $(0.5 \%)$, and haemoglobin $\mathrm{D} / \mathrm{S}$ trait $(0.7 \%)$. The onset of the diseases was most prominent in neonatal to childhood period (0-15 years), followed by reproductive age group (16-45 years). Few cases of old age (46+ years) were detected only when they faced clinical complications (Table 2).

This study found many variations in the clinical presentation of disease (Table 3 ). Patients belonging to $\beta$ thalassemia minor group had mild anaemia with decreased total $\mathrm{Hb}(P=0.001)$ and $\mathrm{Hb} \mathrm{A}(P=0.001)$ compared to normal. Haemoglobin electrophoresis showed a slight increase in $\mathrm{HbA}_{2}$ and $\mathrm{F}$. Since these patients inherit one gene of $\beta$-thalassemia, they are either asymptomatic or develop mild-to-moderate anaemia. Though sometimes the red blood cells may be hypochromic and microcytic, iron supplementation is not required except for pregnant woman. Genetic counselling for couples at risk for offspring with homozygous $\beta$-thalassemia may be done at this stage.

$\mathrm{Hb}$ E- $\beta$-thalassemia was detected in $13.5 \%$ of the overall study population. Patients belonging to this group were severely anaemic with a significant decrease in total $\mathrm{Hb}(P=$ $0.001)$ and $\mathrm{Hb}$ A levels $(P=0.001)$. E- $\beta$-thalassemia patients inherit one gene for $\beta$-thalassemia and one gene for $\mathrm{Hb} \mathrm{E}$ disease. As a result their clinical presentation is similar to those of $\beta$-thalassemia major or $\mathrm{HbE}$ disease, except that they showed greater elevation in $\mathrm{HbE}$ and $\mathrm{F}$ among all the groups studied. Many other studies also reported E- $\beta$-thalassemia as the commonest form of thalassemia in southeast Asia $[6,10,11]$.

$\mathrm{HbE}$ disease and $\mathrm{E}$ trait are homozygotic and heterozygotic conditions of a $\beta$-chain variant, where a lysine residue is substituted by glutamic acid. This monogenic disease also has a broad distribution throughout the Mediterranean, the Middle East, and the Indian subcontinent [12, 13]. This study found $9.2 \% \mathrm{Hb}$ E disease and $12.1 \% \mathrm{Hb}$ E trait among the overall study subjects. The haematological parameters in $\mathrm{HbE}$ disease were similar with $\beta$-thalassemia major with the exception that $\beta$-thalassemic patients had a very high level of $\mathrm{Hb} \mathrm{F}$ and absence of $\mathrm{Hb} \mathrm{E}$. $\mathrm{Hb}$ E-trait patients had milder anaemia comparable to $\beta$-thallasemia minor with significantly higher levels of $\mathrm{Hb} \mathrm{E}(P=0.001)$.

In $\beta$-thalassemia major, as expected, there was severe anaemia with extremely low total $\mathrm{Hb}$ with hypochromia and microcytosis. There was also a significant decrease in $\mathrm{HbA}$ and increase in $\mathrm{Hb}$ F levels. This finding is consistent with a different study by Pootrakul et al. [14]. $\delta$ - $\beta$-Thalassemia is similar to $\beta$-thalassemia major, but symptoms are milder. This study found only a slight increase in $\mathrm{Hb}$ F level still, much less compared to $\beta$-thalassemia major patients. The gene controlling delta chain production is located very close to beta gene on chromosome 11. If one gene is deleted then the other may be affected. Most of the patients of $\delta$ $\beta$-thalassemia survive to adult life with minimal transfusion requirement.

$\mathrm{Hb} \mathrm{D/S}$ trait is a heterozygotic condition where either one $\mathrm{Hb} \mathrm{D}$ or $\mathrm{S}$ chain is combined with one normal $\beta$ chain. Both $\mathrm{D}$ and $\mathrm{S}$ are variants of beta chain, in which a single amino acid is replaced. In $\mathrm{Hb} \mathrm{S}$ the beta subunit has the amino acid valine at position 6 instead of glutamic acid, whereas in $\mathrm{Hb} \mathrm{D}$ glutamine replaces glutamic acid at 121 positions on beta chain. Sickle cell disease is most common in people of African ancestry and tribal people of India. The carrier frequency of sickle gene is cited 1 in 10 in the USA and may be higher in Canada where the black population is composed largely of individuals of Caribbean and African origin [15]. $\mathrm{Hb} \mathrm{D}$ on the other hand occurs mainly in northwest India, Pakistan, and Iran [16]. The frequency of $\mathrm{Hb} \mathrm{D} / \mathrm{S}$ trait found in this study was $0.7 \%$, higher than $\delta$ - $\beta$-thalassemia, or $\beta$ thalassemia major. The electrophoretic mobility of Hb D and $\mathrm{Hb} \mathrm{S}$ is identical at alkaline $\mathrm{pH}$ in cellulose acetate. So, this study could not differentiate them. However, they can be distinguished on citrate-agar electrophoresis at pH 6.2 [17].

\section{Conclusion}

$\beta$-thalassemia minor $(21.3 \%)$ is the commonest encountered haemoglobin formation disorders followed by $\mathrm{E}-\beta$ thalassemia (13.5\%), HbE trait (12.1\%), and $\mathrm{HbE}$ disease $(9.2 \%)$ in Bangladesh. Since these patients were referred from peripheral regions of the country where the diagnostic facility is not much available, this data is representative of an overall prevalence of haemoglobinopathies and thalassemias 
of the country. An effective strategy of preventing the progression of the disease in Bangladesh might be a nationwide screening program employing more sophisticated techniques like polymerase chain reaction (PCR) followed by direct sequencing, genetic counseling, and creating public awareness.

\section{References}

[1] H. U. Shekhar, Y. Kabir, M. Hossain et al., "Blood transfusionmediated viral infections in thalassemic children in Bangladesh," Journal of Medical Sciences, vol. 7, no. 1, pp. 131-135, 2007.

[2] D. J. Weatherall and J. B. Clegg, "Thalassemia-a global public health problem,” Nature Medicine, vol. 2, no. 8, pp. 847-849, 1996.

[3] R. S. Balgir, "The genetic burden of hemoglobinopathies with special reference to community health in India and the challenges ahead," Indian Journal of Hematology and Blood Transfusion, vol. 20, no. 1, pp. 2-7, 2002.

[4] K. Ruzicka, M. Veitl, R. Thalhammer-Scherrer, and I. Schwarzinger, "New hematology analyzer Sysmex XE-2100: performance evaluation of a novel white blood cell differential technology," Archives of Pathology and Laboratory Medicine, vol. 125, no. 3, pp. 391-396, 2001.

[5] N. F. Oliver and D. J. Weatherall, "Thaseemias," in Pediatrics Hematology, S. J. Lilleyman, I. M. Hann, and V. S. Banchette, Eds., pp. 307-327, 2nd edition, 1999.

[6] E. George and H. B. Wong, "Hb E- $\beta^{+}$-thalassaemia in west Malaysia: clinical features in the most common betathalassaemia mutation of the Malays [IVS $1-5(\mathrm{G} \rightarrow \mathrm{C})$ ]," Singapore Medical Journal, vol. 34, no. 6, pp. 500-503, 1993.

[7] R. K. Marwaha and A. Lal, "Present status of hemoglobinopathies in India," Indian Pediatrics, vol. 31, no. 3, pp. 267-271, 1994.

[8] N. Win, A. A. Lwin, M. M. Oo, K. S. Aye, Soe-Soe, and S. Okada, "Hemoglobin E prevalence in malaria-endemic villages in Myanmar," Acta Medica Okayama, vol. 59, no. 2, pp. 63-66, 2005.

[9] S. Fucharoen and P. Winichagoon, "Hemoglobinopathies in Southeast Asia: molecular biology and clinical medicine," Hemoglobin, vol. 21, no. 4, pp. 299-319, 1997.

[10] S. Fucharoen, P. Ketvichit, P. Pootrakul, N. Siritanaratkul, A. Piankijagum, and P. Wasi, "Clinical manifestation of $\beta$-thalassemia/hemoglobin E disease," Journal of Pediatric Hematology/Oncology, vol. 22, no. 6, pp. 552-557, 2000.

[11] H. Lehmann and R. B. Singh, "Hæmoglobin E in Malaya," Nature, vol. 178, no. 4535, pp. 695-696, 1956.

[12] N. Win, T. Harano, K. Harano et al., "A wider molecular spectrum of $\beta$-thalassaemia in Myanmar," British Journal of Haematology, vol. 117, no. 4, pp. 988-992, 2002.

[13] A. V. S. Hill, "Molecular epidemiology of the thalassaemias (including haemoglobin E)," Bailliere's Clinical Haematology, vol. 5, no. 1, pp. 209-238, 1992.

[14] P. Pootrakui, P. Wasi, and S. Na Nakorn, "Haematological data in 312 cases of $\beta$ thalassaemia trait in Thailand," British Journal of Haematology, vol. 24, no. 6, pp. 703-712, 1973.

[15] R. Grover, S. Shahidi, B. Fisher, D. Goldberg, and D. Wethers, "Current sickle cell screening program for newborns in New York City, 1979-1980," American Journal of Public Health, vol. 73, no. 3, pp. 249-252, 1983.

[16] F. Firkin, C. Chesterma, D. Penington, and B. Rush, "Disorders of hemoglobin structure and synthesis," in de Gruchi's Clinical
Haematology in Medical Practice, pp. 137-171, Blackwell Science, Oxford, UK, 5th edition, 1996.

[17] Y. T. Zeng, S. Z. Huang, L. D. Zohu et al., "Identification of hemoglobin D Punjab by gene mapping," Hemoglobin, vol. 10, no. 1, pp. 87-90, 1986. 


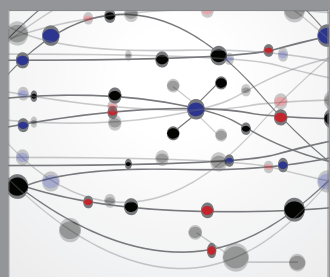

The Scientific World Journal
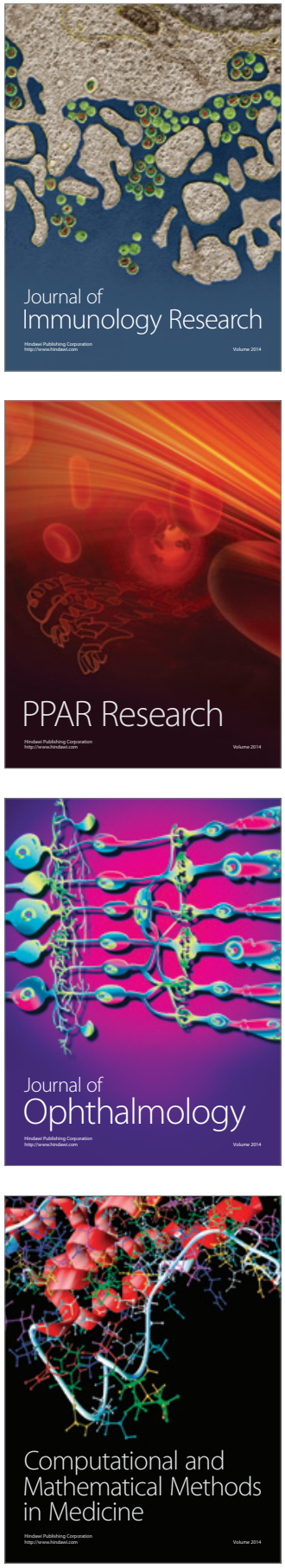

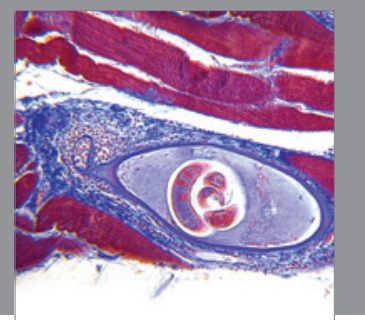

Gastroenterology

Research and Practice
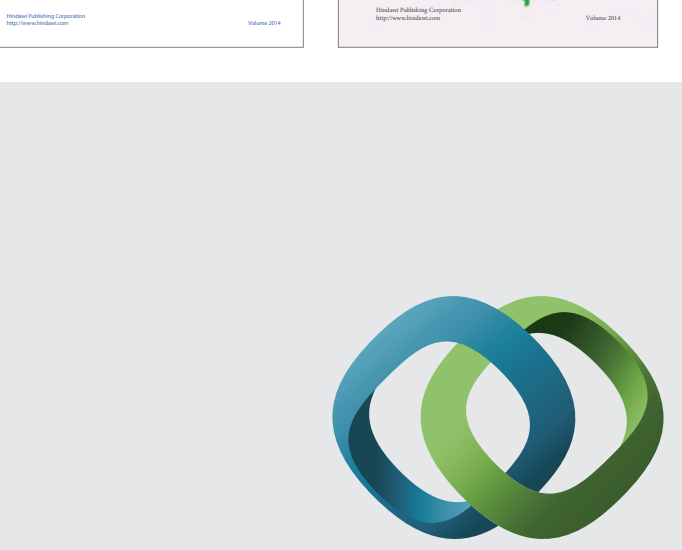

\section{Hindawi}

Submit your manuscripts at

http://www.hindawi.com
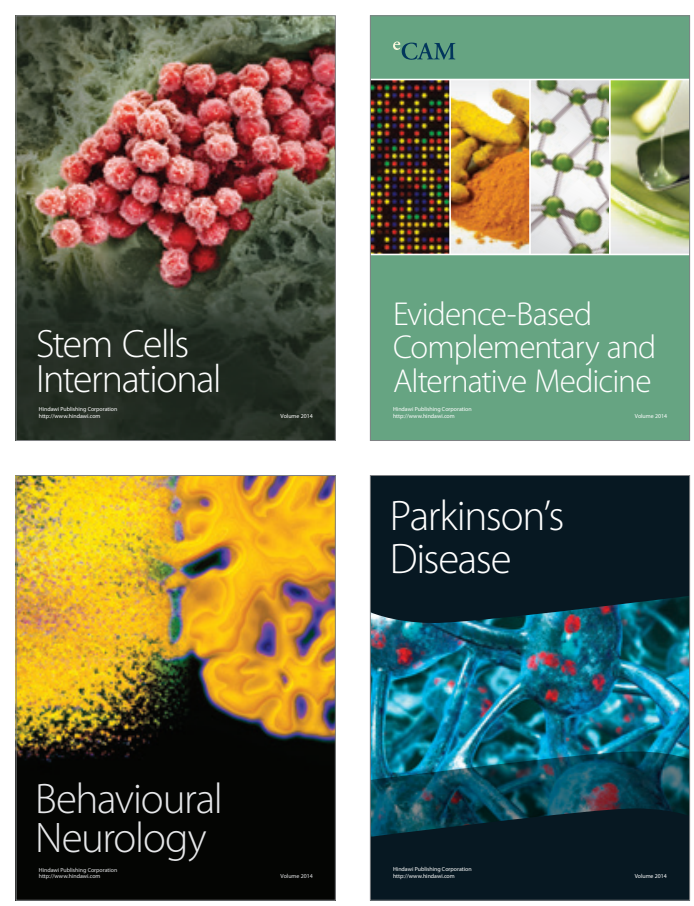

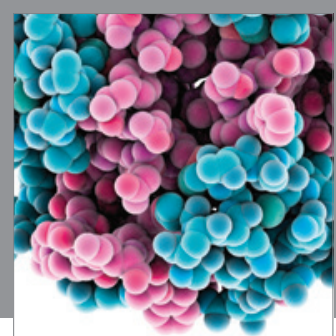

Journal of
Diabetes Research

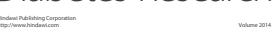

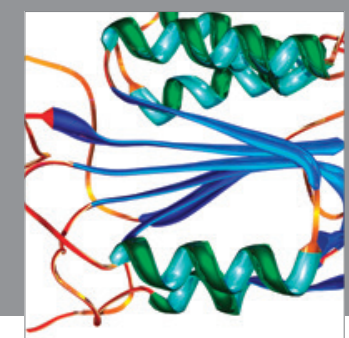

Disease Markers
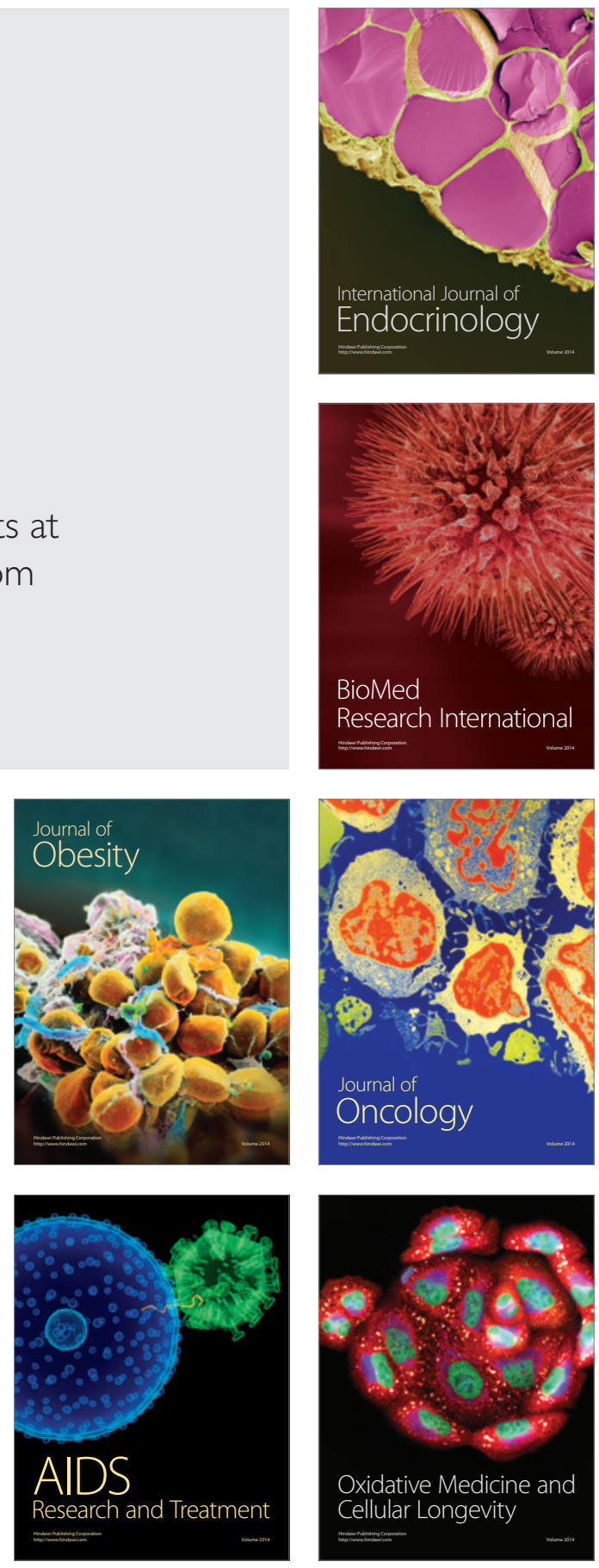